\title{
The structural and spectroscopic basis for modelling prion protein interactions
}

\author{
Jim Warwicker* and Chris Cole \\ Department of Biomolecular Sciences, UMIST, PO Box 88, Manchester M60 1QD, UK
}

\begin{abstract}
Mammalian prion diseases are characterised by an $\alpha$-helical to $\beta$-sheet conformational change within the prion protein, that was originally established with circular dichroism (CD) and Fourier transform infrared (FTIR) spectroscopy. Since prion disease is transmissible, significant effort has been aimed at establishing the molecular details of conformational change and the specificity that underpins infectivity. The structure determined for the carboxy-terminal domain of the predominantly $\alpha$-helical form by nuclear magnetic resonance (NMR) provides a starting point for considering questions at the molecular level. However, elucidation of atomic detail for the $\beta$-rich form is complicated by problems of protein solubility, and regions other than the carboxy-terminal domain of the $\alpha$-rich form are likely to possess functionally significant, ordered domains in the presence of suitable ligands and solution conditions. Further spectroscopic analysis, particularly of polypeptide secondary structure, is playing a key role in constraining molecular modelling studies of prion protein folding and interactions. We present a review of this area of prion research.
\end{abstract}

\section{Introduction}

Transmissible spongiform encephalopathies (TSEs) are a major research focus due to their potential for transmission mediated by protein conformational change, and to the link between bovine spongiform encephalopathy (BSE) and vCJD (variant Creutzfeldt-Jakob disease) in humans [6,21]. The protein-only hypothesis for prion diseases $[18,40]$ proposes that conformational changes of the prion protein $(\operatorname{PrP})$ are responsible for propagation of the scrapie form $\left(\mathrm{PrP}^{\mathrm{Sc}}\right)$ through recruitment of the normal, cellular form $\operatorname{PrP}^{\mathrm{C}}$. This method of $\mathrm{PrP}^{\mathrm{Sc}}$ growth fits into a scheme in which prion disease can be initiated through genetic mutation in familial disease (e.g., mutations that destabilise $\operatorname{PrP}^{\mathrm{C}}$ ), through stochastic conformational events (sporadic disease), and through transmission by the infectious agent (e.g., vCJD or kuru). Whilst the prion hypothesis is not yet proven, in that no infectivity has yet been reported to initiate with recombinant $\operatorname{PrP}$ (which is therefore not derived from brain), no co-purifying nucleic acid genome has been found. For reviews, see, for example, [40,41] (molecular biology of prion diseases); [12] (TSEs and $\mathrm{vCJD}$ ); $[8,11]$ (the role of PrP folding in prion diseases).

Various aspects of PrP biology make it a difficult system in which to probe structure and ligand binding. PrP is a cell surface protein, anchored to the membrane through a glycosylphosphatidylinositol (GPI) moeity [40], with some evidence of cycling between cell surface and interior [20]. Structural analysis by NMR has relied on recombinant protein, lacking the GPI anchor and in the absence of the membrane environment that could alter conformational preferences. The natural function of $\mathrm{PrP}^{\mathrm{C}}$ is currently unknown, although it could involve a copper-mediated role in catalysis or transport [4]. Knocking out the PrP gene in mice has no apparent affect on health [45]. Whilst a range of potential binding partners for PrP have surfaced through direct and indirect assays of protein-protein interactions, e.g., [14,37],

\footnotetext{
*Corresponding author. Tel.: +44 161200 4490; Fax: +44 161236 0409; E-mail: jim.warwicker@ umist.ac.uk.
} 
none has been unambiguously associated with function. Structural studies are therefore carried out with a dearth of knowledge regarding ligands of PrP, either in natural function or in the disease process. There is also uncertainty about the functionally-relevant oligomeric states of $\operatorname{PrP}^{\mathrm{C}}$, which is monomeric in the conditions studied with solution NMR, but apparently dimeric in other conditions [33]. The low water-solubility of $\operatorname{PrP}^{\mathrm{Sc}}$ further complicates structural analysis.

Since PrP conformation is a key focus for understanding prion transmissibility and the targetting of potential therapeutics, opportunities exist for spectroscopic techniques such as FTIR, CD, fluorescence correlation spectroscopy (FCS), and perhaps solid state NMR, e.g., [16], to probe PrP structure. This article looks at the contributions that such methods are making to the mammalian prion field, and demonstrates the potential for an alliance with molecular modelling.

\section{Structural domains of PrP}

\subsection{The amino-terminal sequence, including the repeat region}

Figure 1 gives a schematic view of our current knowledge of domains, and associated structures, for PrP. At the amino-terminus (N-terminus), between the signal sequence and the repeat region, a pre-repeat segment of roughly 30 amino acids exhibits some conservation across species that may be indicative of a functional role. The repeat region (with 4 perfect copies of the peptide PHGGGWGQ stretching from residues 60-91 in human PrP) binds copper ions both in representative peptides [24] and in full length $\mathrm{PrP}$ in vitro and in vivo [3]. Current discussion centres around postulating a role for this region in superoxide dismutase activity [4] or in copper transport/homeostasis [50]. Although the repeats are flexible in NMR conditions, electron paramagnetic resonance (EPR) and CD spectroscopy have identified $\mathrm{Cu}^{2+}$ binding sites and a plausible model for $\mathrm{pH}$-dependent $\mathrm{Cu}^{2+}$ ligation has been proposed, with nitrogen atoms from histidine imidazole and backbone amide groups contributing, as well as backbone amide carbonyls $[2,49]$. An alternative ligation scheme that places more emphasis on histidine sidechains, with

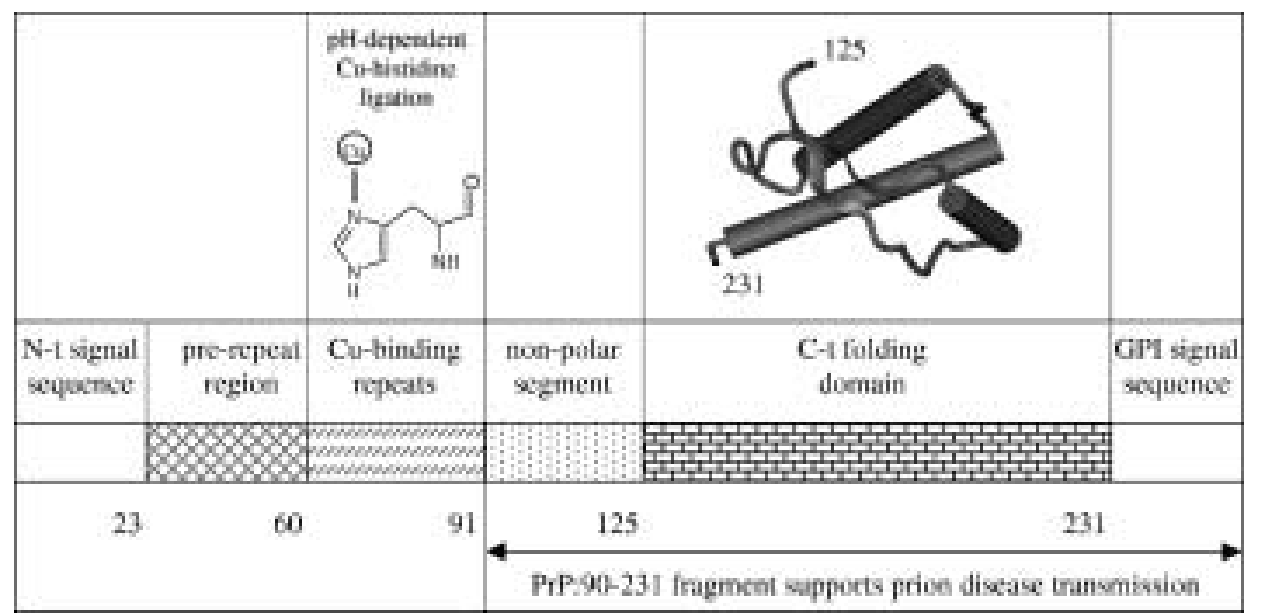

Fig. 1. A schematic of the PrP amino acid sequence, with numbering according to human PrP. The N-t and C-t:GPI signal sequences are cleaved in production of the mature, GPI-anchored protein. With currently investigated solution conditions and ligand availability, only the PrP:125-231 domain shows an ordered 3D structure. 
much higher affinity for $\mathrm{Cu}^{2+}$ ions, has been suggested from a recent fluorescence and NMR spectroscopy study of PrP fragments [27].

A distinguishing feature of $\mathrm{PrP}^{\mathrm{Sc}}$ tends to be the presence of a protease-resistant fragment from about residue 90 to the carboxy-terminus (C-terminus) that excludes the repeats [40], although infectivity has been found in the absence of detectable protease-resistant PrP [30]. Transgenic mice lacking wild-type PrP, but carrying a gene for the truncated version PrP:90-231, are susceptible to prion infection demonstrating that the repeat region is not necessary for for disease propagation [13]. More detailed analysis indicates however that such transmission is significantly slower than that with host-encoded full length $\operatorname{PrP}[15]$.

\subsection{The C-terminal domain, structured in solution NMR conditions}

Moving to the C-terminus, PrP in vivo is anchored (GPI) to the membrane. Preceding the anchor site, solution NMR has established a stable folding domain [42]. This domain (see Fig. 1) is predominantly $\alpha$-helical, with a small $\beta$-sheet structure comprised of two strands, and covers from residues 125 to the C-terminus.

\subsection{The highly conserved and functionally important intermediate region}

Between the repeat region and the C-terminal domain visualised by solution NMR (and slightly overlapping this domain), lies the most conserved stretch of amino acids in PrP. This region bears a large number of small, non-polar amino acid sidechains. It is vital for prion transmission, since N-terminal deletions that go past the repeats remove susceptibility to disease in transgenic mice [13]. Peptides modelled on this sequence are effective inhibitors of $\mathrm{PrP}^{\mathrm{C}}$ to $\mathrm{PrP}^{\mathrm{Sc}}$ conversion in a cell-free assay [9]. The region is also implicated in protein-protein interactions, since both $\operatorname{PrP}^{\mathrm{Sc}}$ and the $\operatorname{PrP}: 106-126$ peptide bind to $\operatorname{PrP}^{\mathrm{C}}$ at a region that includes residues 112-119 [5]. It is therefore reasonable to postulate that the segment is crucial in making the $\operatorname{PrP}$ dimer that is observed in natural $\operatorname{PrP}^{\mathrm{C}}$, purified from brain fractions. Observations with the cell-free reaction system indicate that large-scale structural conversion (of the $\operatorname{PrP}^{\mathrm{C}}$ to $\operatorname{PrP}^{\mathrm{Sc}}$ type) occurs subsequent to initial binding [22]. It is likely that ordered polypeptide is associated with protein-protein interactions and the initial binding step, with which the $90-125$ region is implicated.

\section{Secondary and tertiary structure characterisations of PrP}

Determination of secondary structure in the various $\operatorname{PrP}$ forms underlies our understanding of conformational $\mathrm{PrP}^{\mathrm{C}}$ and $\mathrm{PrP}^{\mathrm{Sc}}$ conformational properties. Analysis of $\mathrm{PrP}^{\mathrm{C}}$ by FTIR gave values of $42 \%$ $\alpha$-helix, little $\beta$-sheet (3\%), and was confirmed by CD [38]. The same study reported the content of $\mathrm{PrP}^{\mathrm{Sc}}$ at 30\% $\alpha$-helix and 43\% $\beta$-sheet, whilst $\mathrm{PrP} 27-30$ (N-terminally truncated $\mathrm{PrP}^{\mathrm{Sc}}$ with proteolysis at around residue 90) displayed $21 \% \alpha$-helix and $54 \% \beta$-sheet. Other work gives helix and sheet content for $\operatorname{PrP}^{\mathrm{Sc}}$ at $20 \%$ and $34 \%$, and these values for $\operatorname{PrP} 27-30$ at $0 \%$ and $43 \%$ [46], with further values for $\operatorname{PrP} 27-30$ at $17 \% \alpha$-helix and $47 \% \beta$-sheet [7]. Although these reports differ in detail, particularly on the degree of $\alpha$-helical structure in $\operatorname{PrP} 27-30$, it became clear that $\operatorname{PrP}^{\mathrm{C}}$ to $\operatorname{PrP}^{\mathrm{Sc}}$ transition is accompanied by an increase in $\beta$-sheet and a decrease in $\alpha$-helix. Furthermore, it was apparent from FTIR that some of the $\beta$-sheet structure of $\mathrm{PrP}^{\mathrm{Sc}}$ was involved in intermolecular interactions, which could form the basis for amyloid formation [17]. 
The predominantly $\alpha$-helical structure of the C-terminal domain of $\operatorname{PrP}^{\mathrm{C}}$ determined by solution NMR [42], is in line with the earlier secondary structure determinations. Since this first 3D NMR report for PrP:121-231, there have been further structural studies of full length PrP, and PrP:90-231, from species that include mouse [43], Syrian hamster [28], bovine [32] and human [54]. However, in the conditions of the solution NMR experiments, no significant ordering is observed outside of the C-terminal domain. The overall fold of the $\mathrm{C}$-terminal domain is conserved through the species studied. Our current knowledge of tertiary structure within $\operatorname{PrP}^{\mathrm{C}}$ therefore resides in the predominantly helical C-terminal domain and a local model for copper coordination in the repeat region, whilst we lack information concerning potential structure in the intermediate and highly conserved region. In fact the fold of the C-terminal domain also appears in the PrP-Dpl protein [34]. The Dpl protein was discovered as an up-regulated gene product in mice lacking the PrP gene [35]. Dpl lacks the repeat region and the highly conserved segment, and like PrP its function is not yet known.

Structural studies with $\mathrm{PrP}^{\mathrm{Sc}}$ are difficult, owing to the solubility problems that associate with amyloidosis. Solubilisation of PrP 27-30 through a reverse micelle system that yields monomeric and dimeric PrP, has allowed the formation of small 2- and 3-dimensional crystals [53]. Although the reported diffraction (up to $1.85 \mathrm{~nm}$ ) is low, refinement of preparation methods could lead to significant structural information on the $\beta$-rich form of PrP. A common alternative has been to study peptides of PrP, varying solvent conditions to give changes in peptide secondary structure. For example, X-ray diffraction of dehydrated peptides that cover the highly conserved segment, gives $\beta$-strand and turn structures [25], and NMR has been employed to study a variety of PrP peptides [31].

Comparisons are commonly made between the $\alpha$-helical to $\beta$-sheet transition that accompanies $\operatorname{PrP}^{\mathrm{Sc}}$ formation from $\mathrm{PrP}^{\mathrm{C}}$, and amyloid diseases in general, in which $\beta$-structure plays a key role in locking together fibrillar structures. Indeed, it appears that partial denaturing conditions can favour the formation of aggregates for many proteins, whether implicated in amyloidoses or not [10]. In making such comparisons it is worth recalling that prion diseases are infectious, indicative of a high affinity interaction path between $\operatorname{PrP}^{\mathrm{Sc}}$ and host $\mathrm{PrP}^{\mathrm{C}}$. This feature (not common to other amyloid diseases) combines with the change to $\beta$-structure, and most likely a seeded polymerisation process, in prion pathogenesis. The next sections discuss two areas which rely on spectroscopic characterisation to probe stages in $\operatorname{PrP}$ conformational transition.

\section{Analysis of $\beta$-rich PrP structures formed in vitro}

There is interest in designing in vitro solution conditions that yield structural changes $(\alpha$ to $\beta)$ and fibril formation with recombinant PrP. There are currently no reports of such "misfolded" PrPs giving rise to infectivity in bioassays. On the other hand it has been possible to reproduce some of the features associated with $\mathrm{PrP}^{\mathrm{Sc}}$, such as $\beta$-rich structure and protease-resistance. Recombinant PrPs have been characterised in spectroscopically-determined $\beta$-rich forms at acidic $\mathrm{pH}$, as equilibrium unfolding intermediates [23,47], and with fibril-forming potential either with a reduced disulphide [26] or in $1 \mathrm{M}$ guanidine-hydrochloride [48]. Other work has stressed the plasticity of recombinant $\operatorname{PrP}$, with $\alpha$-rich or $\beta$-rich forms evident, again depending on the presence of denaturant and the disulphide bond [55].

Solution conditions that destabilise the $\operatorname{PrP}^{C} \mathrm{C}$-terminal domain can lead to formation of a $\beta$-rich form, and these effects can be studied with modelling of structural stability for this domain. For example, calculations of the $\mathrm{pH}$-dependence of stability yield results that are in accord with the appearance of $\beta$-rich forms at acidic $\mathrm{pH}$ [51]. The same argument can be used to rationalise the effects of many of 


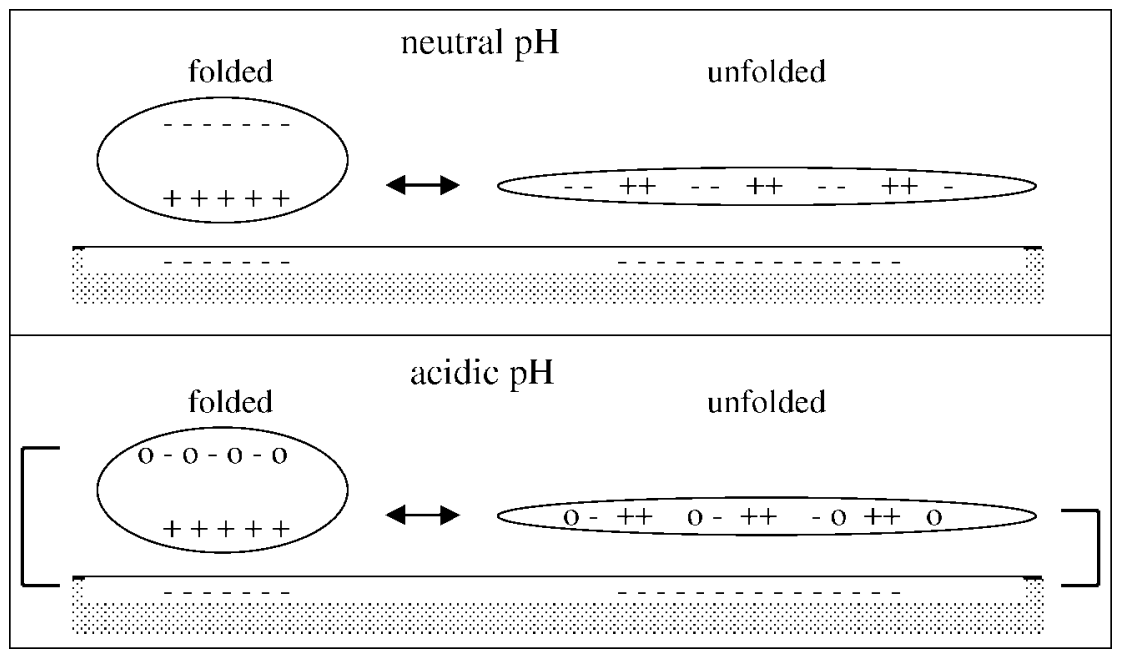

Fig. 2. Model to explain increased dependence of unfolding free energy on membrane proximity at acidic $\mathrm{pH}$, as compared with neutral $\mathrm{pH}$. In this simplified scheme, the folded protein preferentially binds the negatively-charged membrane with a basic surface, and protonation at acidic $\mathrm{pH}$ gives little change in stability since these groups are at relatively long-range from the membrane (left-hand bracket in lower panel). However, the unfolded form is free to contact the membrane over a larger region, and acidic group protonation then gives a larger stabilisation (reducing unfavourable negative to negative charge interactions) than for the folded form (right-hand bracket on the lower panel). The postulated stabilisation of the unfolded form will appear as a reduced unfolding free energy.

the known pathogenic mutations that are associated with familial CJD, i.e., that destabilisation of the $\mathrm{C}$-terminal domain of $\operatorname{PrP}^{\mathrm{C}}$ enhances the formation of $\operatorname{PrP}^{\mathrm{Sc}}$. However, not all such mutations fall into this category [44], reminding us of the need to establish more of the details of the conversion process, structural intermediates, and interacting partners for PrP.

Before looking at modelling aimed at probing structural intermediates, it is of interest to note the potential for analysis of PrP structure at the membrane surface that is afforded by spectroscopic studies in model membrane systems. The possibility that the membrane environment plays a role in the conformational preferences of GPI-anchored PrP is indicated in experiments that show a significant destabilisation of recombinant (non-anchored) $\mathrm{PrP}^{\mathrm{C}}$ structure at $\mathrm{pH} 5$ (but not at $\mathrm{pH}$ 7) in the presence of acidic lipid-containing membrane vesicles [36]. Calculations of $\mathrm{pH}$-dependent stability in the presence of a negatively-charged surface suggest that the observed destabilisation may result from a stabilisation of the unfolded form in this environment at $\mathrm{pH} 5$ [52]. Figure 2 illustrates this hypothesis schematically. The potential for an unfolded form of a protein to contact a membrane more extensively than the folded form could introduce significant effects on the folding free energy, and may have general relevance to membrane-protein interactions. Protein conformational change at a membrane surface is difficult to visualise in atomic detail, but can be followed with spectroscopic probes of secondary and tertiary structure.

\section{Modelling structural change in PrP with reference to spectroscopic constraints}

Molecular modelling is being used in an effort to close the gap between what we know of $\beta$-rich $\operatorname{PrP}$ forms in vitro and the specific interactions that are required to mediate infectivity in vivo. Molecular dynamics simulation of mouse PrP:121-231 indicate that the first few residues could form a transient 


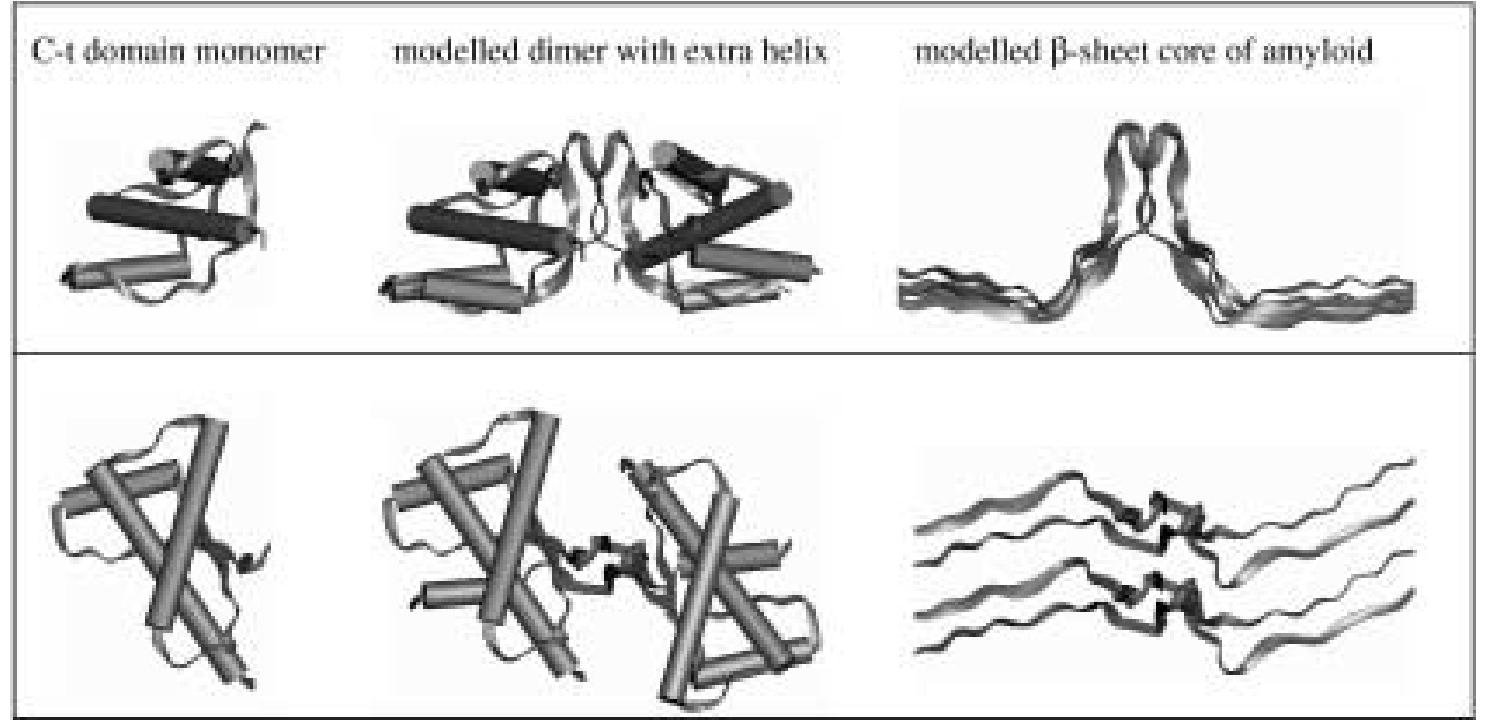

Fig. 3. Model for the formation of a $\beta$-sheet amyloid core, starting with the $\mathrm{C}$-terminal domain fold (left-hand panels), adding the non-polar segment partly as an additional $\alpha$-helix in forming a dimer (central panels), and then using the non-polar $\beta$-sheet regions to form interfaces between dimers in higher order oligomers in which substantial $\alpha$ to $\beta$ structural conversion occurs (right-hand panels). The two layers of this figure show orthogonal views.

$\mathrm{N}$-terminal $\beta$-strand, additional to the $\beta$-structure of the C-terminal domain seen in solution NMR [19], whilst simulations at acidic $\mathrm{pH}$ for a Syrian hamster PrP fragment extending down to residue 109 suggest that these residues could also become involved in formation of an extended $\beta$-sheet [1]. This latter simulation amounts to an estimate of what could happen in the very early stages of acid-induced $\operatorname{PrP}$ refolding to a $\beta$-rich form, and may be difficult to probe experimentally due to the short timescale.

An alternative approach is again to use the C-terminal domain as a starting point, but now looking at conserved sequence and surface features as guide points with which to model-build that part of the highly conserved and non-polar segment that is adjacent to the $\mathrm{C}$-terminal domain. In particular, since this region is implicated in $\operatorname{PrP}-\mathrm{PrP}$ interactions that are likely to involve dimerisation, these factors have been built into a model $\mathrm{PrP}^{\mathrm{C}}$ dimer [52]. The dimer model, and postulated interactions involving the conserved segment then serve as a starting point for considering structural change to $\mathrm{PrP}^{\mathrm{Sc}}$. Figure 3 shows a scheme in which the $\mathrm{C}$-terminal domain dimerises $\left(\mathrm{PrP}^{\mathrm{C}}\right)$ around a core of $\beta$-structure, that is then extended and forms the framework for aggregation into fibrils, with loss of some $\alpha$-helical structure from the original C-terminal domain. This overall scheme for PrP-PrP interactions is consistent with that derived from analysis of the variation in secondary structure and oligomerisation state of recombinant PrP:90-231 as sodium dodecyl sulphate (SDS) concentration is altered [29,39]. In 0.2\% SDS, rPrP:90-231 is soluble, in monomeric form with around $18 \% \alpha$-helix and $22 \% \beta$-sheet. As the SDS concentration is reduced to $0.06 \%$, rPrP:90-231 dimerises with an increase in $\alpha$-helical content of around $4 \%$. Further reduction to $0.02 \%$ SDS gives rise to tetramers or higher oligomers with little change in helical content but around a $10 \%$ increase in sheet. In the absence of SDS an insoluble aggregate is formed. The assessments of secondary structure are made by CD and of oligomeric state by FCS [29]. Presumably the removal of SDS is uncovering non-polar surfaces, which are then involved in forming intermolecular interactions [29], a process which parallels that of the model-building ([52] and Fig. 3). Intriguingly both the modelling and the spectroscopic analysis with SDS variation indicate that dimerisation could be accompanied by 
a modest increase in $\alpha$-helix. These techniques are complentary since the modelling highlights specific regions for conformational change, and can be tested in further rounds of experimentation.

\section{Conclusion}

With the difficulties associated with atomic-level structural characterisation of $\mathrm{PrP}^{\mathrm{Sc}}$ and intermediates on the pathway from $\operatorname{PrP}^{\mathrm{C}}$ to $\mathrm{PrP}^{\mathrm{Sc}}$, it is likely that molecular modelling will play an important complementary role to experiment in identifying regions of conformational change and protein-protein interaction. Accompanying observations are provided by spectroscopic techniques such as CD and FCS. This is an important area in considering potential therapeutics. Conformational variation or interactions that are identified outside of the naturally occuring $\operatorname{PrP}^{\mathrm{C}}$ life cycle, but within $\mathrm{PrP}^{\mathrm{Sc}}$ formation and propagation, are clear targets for therapeutic design (for example, stabilisation against conformational change to $\mathrm{PrP}^{\mathrm{Sc}}$ or disruption of $\mathrm{PrP}^{\mathrm{C}}-\mathrm{PrP}^{\mathrm{Sc}}$ interactions). Such work will progress alongside improved techniques aimed at isolating intermediate structural forms of PrP, at incorporating binding partners, and at mimicking the membrane environment.

\section{Acknowledgements}

The authors thank the UK BBSRC and the EU for financial support.

\section{References}

[1] D.O.V. Alonso, S.J. DeArmond, F.E. Cohen and V. Daggett, Mapping the early steps in the pH-induced conformational conversion of the prion protein, Proc. Natl. Acad. Sci. USA 98 (2001), 2985-2989.

[2] E. Aronoff-Spencer, C.S. Burns, N.I. Avdievich, G.J. Gerfeb, J. Peisach, W.E. Antholine, H.L. Ball, F.E. Cohen, S.B. Prusiner and G.L. Millhauser, Identification of the $\mathrm{Cu}^{2+}$ binding sites in the N-terminal domian of the prion protein by EPR and CD spectroscopy, Biochemistry 39 (2000), 13 760-13 771.

[3] D.R. Brown, K.F. Qin, J.W. Herms, A. Madling, J. Manson, R. Strome, P.E. Fraser, T. Kruck, A. vonBohlen, W. SchulzSchaeffer, A. Giese, D. Westaway and H. Kretzschmar, The cellular prion protein binds copper in vivo, $\mathrm{Na}$ ture 390 (1997), 684-687.

[4] D.R. Brown, B.S. Wong, F. Hafiz, C. Clive, S. Haswell and I.M. Jones, Normal prion protein has an activity like that of superoxide dismutase, Biochem. J. 344 (1999), 1-5.

[5] D.R. Brown, $\operatorname{PrP}^{\mathrm{Sc}}$-like prion peptide inhibits the function of cellular prion protein, Biochem. J. 352 (2000), 511-518.

[6] M.E. Bruce, R.G. Will, J.W. Ironside, I. McConnell, D. Drummond, A. Suttie, L. McCardle, A. Chree, J. Hope, C. Birkett, S. Cousens, H. Fraser and C.J. Bostock, Transmissions to mice indicate that 'new variant' CJD is caused by the BSE agent, Nature 389 (1997), 498-501.

[7] B.W. Caughey, A. Dong, K.S. Bhat, D. Ernst, S.F. Hayes and W.S. Caughey, Secondary structure-analysis of the scrapieassociated protein PrP 27-30 in water by infrared-spectroscopy, Biochemistry 30 (1991), 7672-7680.

[8] B. Caughey and B. Chesebro, Prion protein and the transmissible spongiform encephalopathies, Trends Cell Biol. 7 (1997), $56-62$.

[9] J. Chabry, S.A. Priola, K. Wehrly, J. Nishio, J. Hope and B. Chesebro, Species-independent inhibition of abnormal prion protein (PrP) formation by a peptide containing a conserved PrP sequence, J. Virol. 73 (1999), 6245-6250.

[10] F. Chiti, P. Webster, N. Taddei, A. Clark, M. Stefani, G. Ramponi and C.M. Dobson, Designing conditions for in vitro formation of amyloid protofilaments and fibrils, Proc. Natl. Acad. Sci. USA 96 (1999), 3590-3594.

[11] F.E. Cohen, Protein misfolding and prion diseases, J. Mol. Biol. 293 (1999), 313-320.

[12] J. Collinge, Variant Creutzfeldt-Jakob disease, The Lancet 354 (1999), 317-323.

[13] M. Fischer, T. Rülicke, A. Raeber, A. Sailer, M. Moser, B. Oesch, S. Brandner, A. Aguzzi and C. Weissmann, Prion protein (PrP) with amino-proximal deletions restoring susceptibility of PrP knockout mice to scrapie, EMBO J. 15 (1996), 1255-1264. 
[14] M.B. Fischer, C. Roeckl, P. Parizek, H.P. Schwarz and A. Aguzzi, Binding of disease-associated prion protein to plasminogen, Nature 408 (2000), 479-483.

[15] E. Flechsig, D. Shmerling, I. Hegyi, A.J. Raeber, M. Fischer, A. Cozzio, C. von Mering, A. Aguzzi and C. Weissmann, Prion protein devoid of the octarepeat region restores susceptibility to scrapie in PrP knockout mice, Neuron 27 (2000), 399-408.

[16] R. Fu and T.A. Cross, Solid-state nuclear magnetic resonance investigation of protein and polypeptide structure, Annu. Rev. Biophys. Biomol. Struct. 28 (1999), 235-268.

[17] M. Gasset, M.A. Baldwin, R.J. Fletterick and S.B. Prusiner, Pertubation of the secondary structure of the scrapie prion protein under conditions that alter infectivity, Proc. Natl. Acad. Sci. USA 90 (1993), 1-5

[18] J.S. Griffith, Self-replication and scrapie, Nature 215 (1967), 1043-1044.

[19] C. Guilbert, F. Ricard and J.C. Smith, Dynamic simulation of the mouse prion protein, Biopolymers 54 (2000), 406-415.

[20] D.A. Harris, A. Gorodinsky, S. Lehmann, K. Moulder and S.L. Shyng, Cell biology of the prion protein, Current Topics in Microbiology and Immunology 207 (1996), 77-93.

[21] A.F. Hill, M. Desbruslais, S. Joiner, K.C.L. Sidle, I. Gowland, J. Collinge, L.J. Doey and P. Lantos, The same prion strain causes vCJD and BSE, Nature 389 (1997), 448-450.

[22] M. Horiuchi, S.A. Priola, J. Chabry and B. Caughey, Interactions between heterologous froms of prion proteins: Binding, inhibition of conversion, and species barriers, Proc. Natl. Acad. Sci. USA 97 (2000), 5836-5841.

[23] S. Hornemann and R. Glockshuber, A scrapie-like unfolding intermediate of the prion protein domain $\operatorname{PrP}(121-231)$ induced by acidic pH, Proc. Natl. Acad. Sci. USA 95 (1998), 6010-6014.

[24] M.P. Hornshaw, J.R. McDermott and J.M. Candy, Copper-binding to the N-terminal repeat regions of mammalian and abvian prion protein, Biochem. Biophys. Res. Comm. 207 (1995), 621-629.

[25] H. Inouye and D.A. Kirschner, Polypeptide chain folding in the hydrophobic core of hamster scrapie prion: Analysis by X-ray diffraction, J. Struct. Biol. 122 (1998), 247-255.

[26] G.S. Jackson, L.L.P. Hosszu, A. Power, A.F. Hill, J. Kenney, H. Saibil, C.J. Craven, J.P. Waltho, A.R. Clarke and J. Collinge, Reversible conversion of monomeric human prion protein between native and fibrilogenic conformations, Science 283 (1999), 1935-1937.

[27] G.S. Jackson, I. Murray, L.L.P. Hosszu, N. Gibbs, J.P. Waltho, A.R. Clarke and J. Collinge, Location and properties of metal-binding sites on the human prion protein, Proc. Natl. Acad. Sci. USA (2001), DOI 10.1073/pnas.151038498.

[28] T.L. James, H. Liu, N.B. Ulyanov, S. Farr-Jones, H. Zhang, D.G. Donne, K. Kaneko, D. Groth, I. Mehlhorn, S.B. Prusiner and F.E. Cohen, Solution structure of a 142-residue recombinant prion protein corresponding to the infectious fragment of the scrapie isoform, Proc. Natl. Acad. Sci. USA 94 (1997), 10 086-10 091.

[29] K. Jansen, O. Schafer, E. Birkmann, K. Post, H. Serban, S.B. Prusiner and D. Riesner, Structural intermediates in the putative pathway from the cellular prion protein to the pathogenic form, Biol. Chem. 382 (2001), 683-691.

[30] C.I. Lasmezas, J.-P. Deslys, O. Robain, A. Jaegly, V. Beringue, J.-M. Peyrin, J.-G. Fournier, J.-J. Hauw, J. Rossier and D. Dormont, Transmission of the BSE agent to mice in the absence of detectable abnormal prion protein, Nature 275 (1997), 402-405.

[31] A.Z. Liu, R. Riek, R. Zahn, S. Hornemann, R. Glockshuber and K. Wuthrich, Peptides and proteins in neurodegenerative disease: Helix propensity of a polypeptide containing helix 1 of the mouse prion protein studied by NMR and CD spectroscopy, Biopolymers 51 (1999), 145-152.

[32] F. Lopez-Garcia, R. Zahn, R. Riek, M. Billeter and K. Wüthrich, NMR structure of the bovine prion protein, Proc. Natl. Acad. Sci. USA 97 (2000), 8334-8339.

[33] R.K. Meyer, A. Lustig, B. Oesch, R. Fatzer, A. Zurbriggen and M. Vandevelde, A monomer-dimer equilibrium of a cellular prion protein $\left(\operatorname{PrP}^{\mathrm{C}}\right)$ not observed with recombinant $\operatorname{PrP}^{*}$, J. Biol. Chem. 275 (2000), 38 081-38 087.

[34] H. Mo, R.C. Moore, F.E. Cohen, D. Westaway, S.B. Prusiner, P.E. Wright and H.J. Dyson, Two different neurodegenerative diseases caused by proteins with similar structures, Proc. Natl. Acad. Sci. USA 98 (2001), 2352-2357.

[35] R.C. Moore, I.Y. Lee, G.L. Silverman, P.M. Harrison, R. Strome, C. Heinrich, A. Karunaratne, S.H. Pasternak, M.A. Chishti, Y. Liang, P. Mastrangelo, K. Wang, A.F.A. Smit, S. Katamine, G.A. Carlson, F.E. Cohen, S.B. Prusiner, D.W. Melton, P. Tremblay, L.E. Hood and D. Westaway, Ataxia in prion protein (PrP)-deficient mice is associated with upregulation of the novel PrP-like protein Doppel, J. Mol. Biol. 292 (1999), 797-817.

[36] M. Morillas, W. Swietnicki, P. Gambetti and W.K. Surewicz, Membrane environment alters the conformational structure of the recombinant human prion protein, J. Biol. Chem. 274 (1999), 36 859-36 865.

[37] S. Mouillet-Richard, M. Ermonval, C. Chebassier, J.L. Laplanche, S. Lehmann, J.M. Launay and O. Kellerman, Signal transduction through the prion protein, Science 289 (2000), 1925-1928.

[38] K.-M. Pan, M. Baldiwn, J. Nguyen, M. Gasset, A. Serban, D. Groth, I. Mehlhorn, Z. Huang, R.J. Fletterick, F.E. Cohen and S.B. Prusiner, Conversion of $\alpha$-helices into $\beta$-sheets features in the formation of the scrapie prion proteins, Proc. Natl. Acad. Sci. USA 90 (1993), 10962-10966.

[39] K. Post, M. Pitschke, O. Schafer, H. Wille, T.R. Appel, D. Kirsch, I. Mehlhorn, H. Serban, S.B. Prusiner and D. Ries- 
ner, Rapid acquisition of $\beta$-sheet structure in the prion protein prior to multimer formation, Biol. Chem. 379 (1998), 1307-1317.

[40] S.B. Prusiner, Molecular biology of prion diseases, Science 252 (1991), 1515-1522.

[41] S.B. Prusiner, Molecular biology and pathogenesis of prion diseases, Trends Biochem. Sci. 21 (1996), $482-487$.

[42] R. Riek, S. Hornemann, G. Wider, M. Billeter, R. Glockshuber and K. Wüthrich, NMR structure of the mouse prion protein domain $\operatorname{PrP}(121-231)$, Nature 382 (1996), 180-182.

[43] R. Riek, S. Hornemann, G. Wider, R. Glockshuber and K. Wuthrich, K, NMR characterization of the full-length recombinant murine prion protein, $\mathrm{mPrP}(23-231)$, FEBS Letters 413 (1997), 282-288.

[44] R. Riek, G. Wider, M. Billeter, S. Hornemann, R. Glockshuber and K. Wuthrich, Prion protein NMR structure and familial human spongiform encephalopathies, Proc. Natl. Acad. Sci. USA 95 (1998), 11 667-11 672.

[45] R.D. Rossi, A. Cozzio, E. Flechsig, M.A. Klein, T. Rulicke, A. Aguzzi and C. Weissmann, Onset of ataxia and Purkinje cell loss in PrP null mice inversely correlated with Dpl level in the brain, EMBO J. 20 (2001), 694-702.

[46] J. Safar, P.P Roller, D.C. Gajdusek and C.J. Gibbs, Conformational transitions, dissociation, and unfolding of scrapie amyloid (prion) protein, J. Biol. Chem. 268 (1993), 20 276-20 284.

[47] W. Swietnicki, R. Petersen, P. Gambetti and W.K. Surewicz, pH-dependent stability and conformation of the recombinant human prion protein $\operatorname{PrP}(90-231)$, J. Biol. Chem. 272 (1997), 27 517-27 520.

[48] W. Swietnicki, M. Morillas, S.G. Chen, P. Gambetti and W.K. Surewicz, Aggregation and Fibrillization of the recombinant human prion protein huPrP90-231, Biochemistry 39 (2000), 424-431.

[49] J.H. Viles, F.E. Cohen, S.B. Prusiner, D.B. Goodin, P.E. Wright and H.J. Dyson, Copper binding to the prion protein: Structural implications of four identical cooperative binding sites, Proc. Natl. Acad. Sci. USA 96 (1999), 2042-2047.

[50] D.J. Waggoner, B. Drisaldi, T.B. Bartnikas, R.L.B. Casareno, J.R. Prohaska, J.D. Gitlin and D.A. Harris, Brain copper content and cuproenzyme activity do not vary with prion protein expression level, J. Biol. Chem. 275 (2000), 7455-7458.

[51] J. Warwicker, Modelling charge interactions in the prion protein: predictions for pathogenesis, FEBS Letters 450 (1999), 144-148.

[52] J. Warwicker, Modeling a prion protein dimer: Predictions for fibril formation, Biochem. Biophys. Res. Comm. 278 (2000), 646-652.

[53] H. Wille and S.B. Prusiner, Ultrastructural studies on scrapie prion protein crystals obtained from reverse micellar solutions, Biophys. J. 76 (1999), 1048-1062.

[54] R. Zahn, A. Liu, T. Luhrs, L. Calzolai, C. Von Schroetter, F.L. Garcia, R. Riek, G. Wider, M. Billeter and K. Wüthrich, NMR solution structure of the human prion protein, Proc. Natl. Acad. Sci. USA 97 (2000), 145-150.

[55] H. Zhang, J. Stockel, I. Mehlhorn, D. Groth, M.A. Baldwin, S.B. Prusiner, T.L. James and F.E. Cohen, Physical studies of conformational plasticity in a recombinant prion protein, Biochemistry 36 (1997), 3543-3553. 


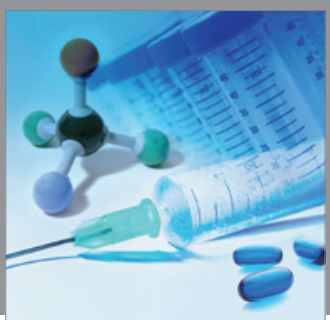

International Journal of

Medicinal Chemistry

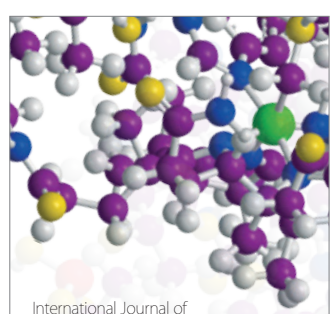

Carbohydrate Chemistry

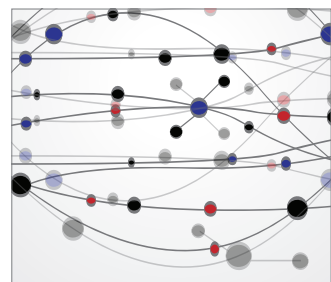

The Scientific World Journal
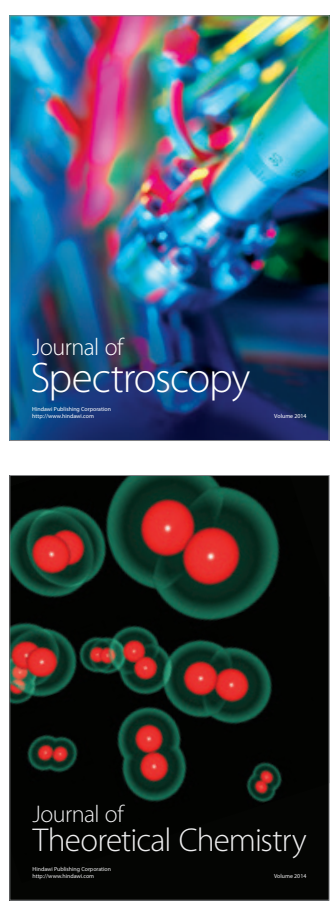
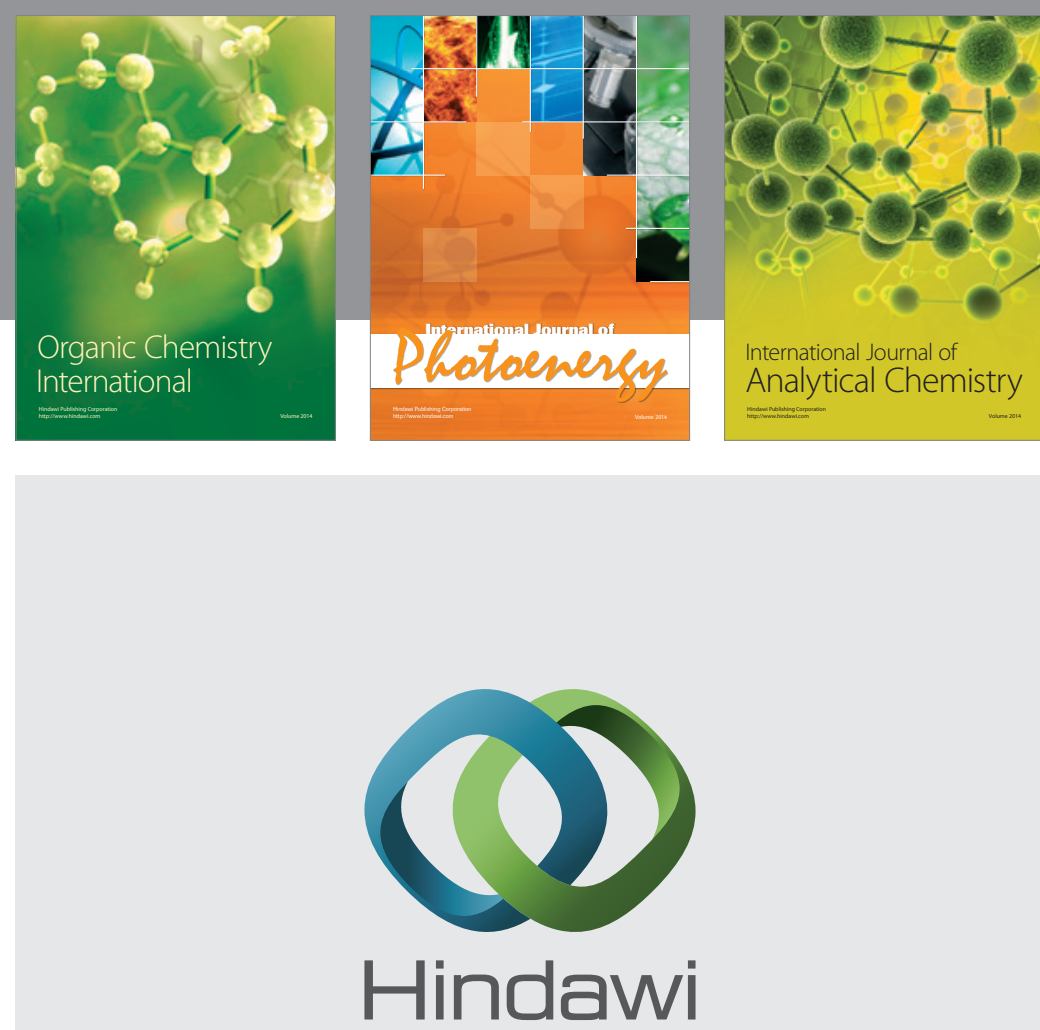

Submit your manuscripts at

http://www.hindawi.com
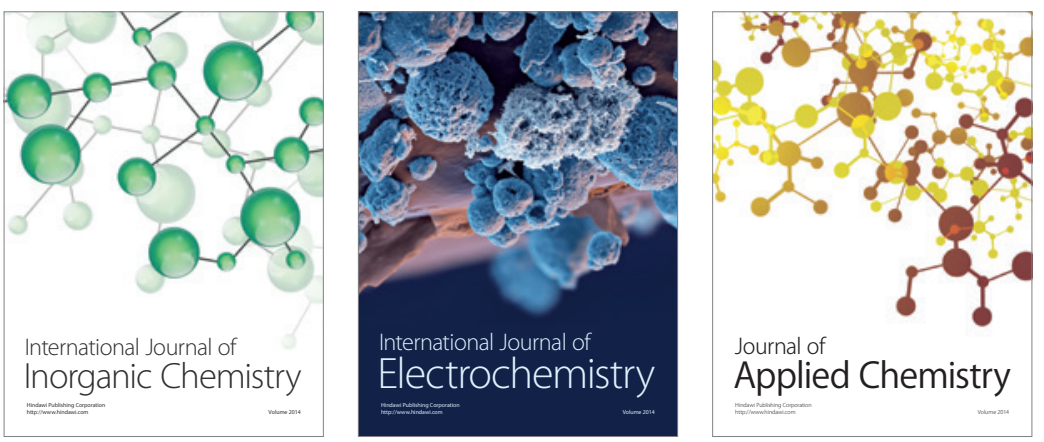

Journal of

Applied Chemistry
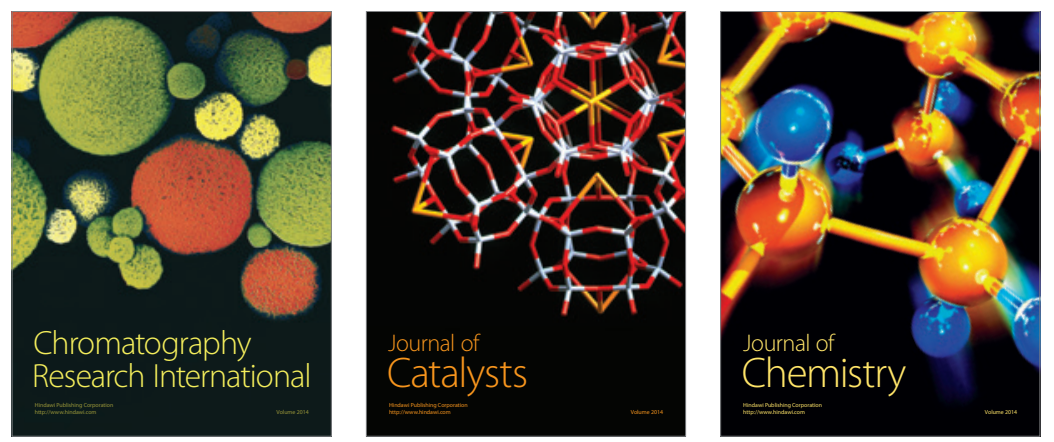
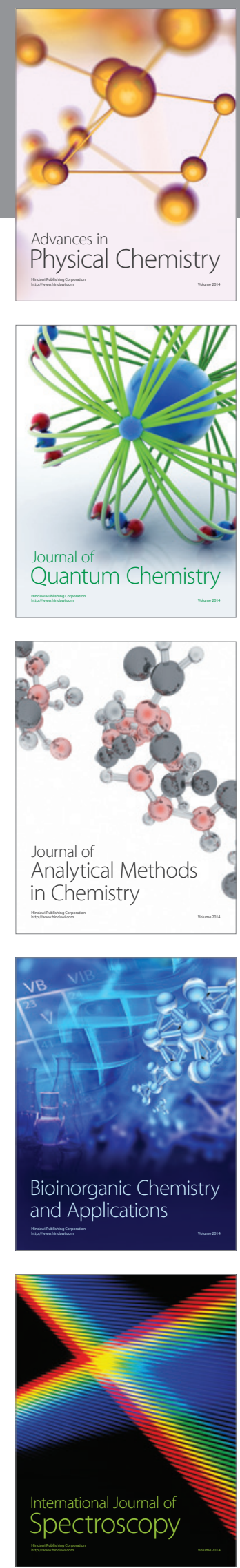